\title{
Neuroprotective effects of verbascoside against Alzheimer's disease via the relief of endoplasmic reticulum stress in $A \beta$ - exposed U251 cells and APP/PS1 mice
}

Chunyue Wang ${ }^{1 \dagger}$, Xueying Cai ${ }^{1 \dagger}$, Ruochen Wang ${ }^{1}$, Siyu Zhai ${ }^{1}$, Yongfeng Zhang ${ }^{1}$, Wenji Hu ${ }^{1}$, Yizhi Zhang ${ }^{2 *}$ and Di Wang ${ }^{1^{*}}$ D

\begin{abstract}
Background: Endoplasmic reticulum (ER) stress is involved in the progression of Alzheimer's disease (AD). Verbascoside (VB), an active phenylethanoid glycoside that was first isolated from Verbascum sinuatum (the wavyleaf mullein), possesses anti-inflammatory, antioxidative, and anti-apoptotic effects. The purpose of this study was to elucidate the beneficial effects of VB in amyloid $\beta(A \beta)_{1-42}$-damaged human glioma (U251) cells and in APPswe/PSEN1dE9 transgenic (APP/PS1) mice.

Methods: U251 cells were co-incubated with $10 \mu \mathrm{M}$ of $A \beta_{1-42}$ and treated with VB. The protective effects of VB were investigated by using 3-(4,5-dimethylthiazole-2-yl)-2,5-diphenyl tetrazolium bromide assay, flow cytometry, fluorescence staining, and transmission electron microscopy. APP/PS1 transgenic mice were treated for 6 weeks with VB. Learning and memory were evaluated using a Morris water maze test. Immunohistochemistry, terminal deoxynucleotidyl transferasemediated deoxyuridine triphosphate nick end labeling, thioflavin-S staining, and proteomics analysis were performed to study the potential neuroprotective mechanism. Enzyme-linked immunosorbent assays and western blot were performed to analyze altered protein levels of brain lysates in APP/PS1 mice and/or A $\beta_{1-42}$-damaged U251 cells.
\end{abstract}

Results: In A $\beta_{1-42}$-damaged U251 cells, VB significantly improved cell viability, inhibited apoptosis, reduced calcium accumulation and the intracellular concentrations of reactive oxygen species, and improved the morphology of mitochondria and ER. In APP/PS1 mice, 6-week administration of VB significantly improved memory and cognition. VB inhibited apoptosis, reduced the deposition of $A \beta$, reduced the formation of neurofibrillary tangles formed by hyperphosphorylated tau protein, and downregulated the expression levels of 4-hydroxynonenal and mesencephalic astrocyte-derived neurotrophic factor in the brains of APP/PS1 mice. Proteomics analysis of mouse hippocampus suggested that the neuroprotective effect of VB may be related to the reduction of ER stress. This was indicated by the fact that VB inhibited the three branches of the unfolded protein response, thereby attenuating ER stress and preventing apoptosis.

Conclusions: The results confirmed that VB possesses significant neuroprotective effects, which are related to the reduction of ER stress. These findings support the status of $\mathrm{VB}$ as a potentially effective treatment for $A D$ and warrant further research.

Keywords: Alzheimer's disease, Verbascoside, Endoplasmic reticulum stress, Unfolded protein response, Aß

\footnotetext{
* Correspondence: yzzhang@jlu.edu.cn; jluwangdi@outlook.com; jluwangdi@jlu.edu.cn

${ }^{+}$Chunyue Wang and Xueying Cai contributed equally to this work.

2Department of Neurology, The Second Hospital of Jilin University, Changchun 130041, China

'School of Life Sciences, Jilin University, Changchun 130012, China
}

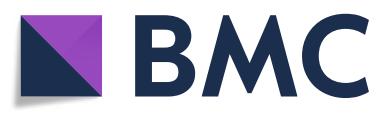

(c) The Author(s). 2020 Open Access This article is licensed under a Creative Commons Attribution 4.0 International License, which permits use, sharing, adaptation, distribution and reproduction in any medium or format, as long as you give appropriate credit to the original author(s) and the source, provide a link to the Creative Commons licence, and indicate if changes were made. The images or other third party material in this article are included in the article's Creative Commons licence, unless indicated otherwise in a credit line to the material. If material is not included in the article's Creative Commons licence and your intended use is not permitted by statutory regulation or exceeds the permitted use, you will need to obtain permission directly from the copyright holder. To view a copy of this licence, visit http://creativecommons.org/licenses/by/4.0/ The Creative Commons Public Domain Dedication waiver (http://creativecommons.org/publicdomain/zero/1.0/) applies to the data made available in this article, unless otherwise stated in a credit line to the data. 


\section{Introduction}

Alzheimer's disease (AD) is a common degenerative brain disease in the elderly $[1,2]$ and is clinically characterized by memory decline and cognitive dysfunction [3]. According to previous reports, approximately 13\% of people aged over 65 develop AD. The quality of life of these individuals is severely reduced due to language and behavioral barriers [4]. Furthermore, patients die within an average of 10 years after their AD diagnosis [5]. The deposition of amyloid $\beta$ (A $\beta)$ and neurofibrillary tangles (NFTs) formed by hyperphosphorylated tau protein are two pathologic hallmarks of $\mathrm{AD}$, which eventually lead to neuronal death and cognitive impairment [6, 7]. As the pathogenesis of AD is unclear, there is a lack of effective early prevention and treatment methods [8]. Although some treatments temporarily relieve AD symptoms, thereby improving the quality of life of patients and reducing caregiver burdens, there is currently no cure for AD, nor a treatment to halt its progression [9].

Drugs approved by the US Food and Drug Administration for $\mathrm{AD}$ include cholinesterase inhibitors (tacrine, rivastigmine, galantamine, and donepezil) and $N$-methylD-aspartate receptor antagonists (memantine) [9, 10]. However, due to its hepatotoxic and gastrointestinal side effects, the cholinesterase inhibitor tacrine was withdrawn from clinical use in 2003 [11], and this group of drugs often cause nausea, diarrhea, vomiting, and unconsciousness $[12,13]$. In addition, memantine increases the risk of hypertension, confusion, and neurological diseases in the elderly [14]. An encouraging potential treatment is GV-971, a sodium oligosaccharide that is extracted from marine plants, which exhibits a good therapeutic effect in patients with mild to moderate $\mathrm{AD}$ by improving the intestinal microenvironment [15]. This compound was approved for AD treatment in China in 2019 (State Drugs Administration License No.: GUOYAOZHUNZI H20190031). In general, plant-derived therapies have attracted the attention of researchers screening candidate agents for various diseases due to their extensive pharmacological activities. For example, verbascoside (VB), also known as acteoside, was first isolated from the herbaceous plant Verbascum sinuatum (the wavyleaf mullein) in 1968 (Additional file 1: Fig. S1). VB is an active phenylethanoid glycoside and possesses significant anti-inflammatory, antioxidative, and antiapoptotic activities, among other biological activities $[16,17]$ and can cross the blood-brain barrier in adult zebrafish [18]. In clinical trials, the platelet aggregation value of patients who took $100 \mathrm{mg} / \mathrm{d}$ of $\mathrm{VB}$ for 2 weeks was significantly reduced, without observable adverse reactions [19]. Studies of the neuroprotective effects of VB have shown that it can increase the memory capabilities of mice with D-galactose- and $\mathrm{AlCl}_{3}$-induced $\mathrm{AD}$ by reducing the expression levels of caspase 3 [20], repair scopolamine-induced memory impairment in ICR mice [21], and inhibit the aggregation of $A \beta$ [22]. Furthermore, the anti-apoptotic effects of VB protect SH-SY5Y (neuroblastoma) cells against $\mathrm{A} \beta$-induced damage [16]. However, systematic in vitro and in vivo studies have not been reported on the neuroprotective effects of $\mathrm{VB}$ with respect to endoplasmic reticulum (ER) stress.

Due to its role in regulating cell apoptosis, ER stress has been reported to be involved in the progression of $\mathrm{AD}$ [23]. It is known that the molecular chaperone immunoglobulin-binding protein (BiP) binds to misfolded or unfolded proteins and releases pressure sensors to stimulate the unfolded protein response (UPR) during ER stress [24]. If ER homeostasis cannot be recovered in time, the UPR fails to resolve these pressure signals from the ER, leading to apoptosis [5]. A feedback loop may develop, in which ER stress promotes $A \beta$ neurotoxicity [25] and enhances tau protein phosphorylation, which further triggers the UPR in neurons, generating a vicious cycle that drives the progression of $A D$ [26]. Astrocytes are widespread in the central nervous system [27] and have been reported to respond to the oligomerization of $\mathrm{A} \beta$ peptides by regulating the release of calcium ions $\left(\mathrm{Ca}^{2+}\right)$ in the ER, which triggers ER stress and causes reactive astrogliosis, ultimately leading to the damaged neuronal signal transmission seen in $\mathrm{AD}$ [28]. Human glioma (U251) cells showing an effective astrogliotic response have been used as an astrocyte model to investigate the expression of glial fibrillary acidic protein and Toll-like receptors in previous studies $[29,30]$, and $A \beta_{1-42}$-damaged U251 cells are commonly used as a typical in vitro AD model [31, 32].

In this study, we explored the neuroprotective effects of $\mathrm{VB}$ in A $\beta$-damaged U251 cells and APPswe/ PSEN1dE9 transgenic (APP/PS1) mice. We used proteomics, western blot, and enzyme-linked immunosorbent assay (ELISA) techniques to determine whether the neuroprotective effects of $\mathrm{VB}$ against $\mathrm{AD}$ were related to the regulation of ER stress. The resulting data provide a theoretical basis for the further investigation of the neuroprotective properties of VB.

\section{Materials and methods \\ Cell culture}

U251 cells were obtained from the BeNa Culture Collection (No. BNCC337874) (Beijing, China) and cultured in Dulbecco's modified Eagle's medium (Gibco, Thermo Fisher Scientific, Waltham, MA, USA) supplemented with $10 \%$ fetal bovine serum (Zhejiang Tianhang Biotechnology Co., Ltd., Huzhou, China), 1\% $100 \mu \mathrm{g} / \mathrm{mL}$ streptomycin, and 100 units/mL penicillin (Gibco, Thermo Fisher Scientific, Waltham, MA, USA) in a humidified $5 \% \mathrm{CO}_{2}$ incubator at $37^{\circ} \mathrm{C}$. 


\section{Cell viability assay}

U251 cells were seeded into 96-well plates at a density of $8 \times 10^{3}$ cells per well. After $12 \mathrm{~h}$ of incubation, cells were pretreated with VB (Cas No. 61276-17-3, purity 98.38\%, Chengdu Herb-purify Co., Ltd., China) for $3 \mathrm{~h}$ at doses of 0.25 and $1 \mu \mathrm{M}$, and then co-incubated with or without $10 \mu \mathrm{M}$ of $\mathrm{A} \beta_{1-42}$ (052487, Gill Biochemical Co., Ltd., Shanghai, China) at $37{ }^{\circ} \mathrm{C}$ for a further $24 \mathrm{~h}$. Twenty microliters of 3-(4,5-dimethylthiazole-2-yl)-2,5diphenyl tetrazolium bromide $(5 \mathrm{mg} / \mathrm{mL})$ was added to each well, and the cells were further incubated for $4 \mathrm{~h}$ at $37{ }^{\circ} \mathrm{C}$ in darkness. After removing the supernatant, 150 $\mu \mathrm{L}$ of dimethyl sulfoxide were added to dissolve crystalline formazan. The absorbance at $490 \mathrm{~nm}$ was measured using a microplate reader (Synergy 4, Omega Bio-tek, Inc., Norcross, GA, USA).

\section{Measurement of intracellular reactive oxygen species (ROS) and $\mathrm{Ca}^{2+}$ concentrations}

As before [33], U251 cells were seeded into 6-well plates at a density of $2 \times 10^{5}$ cells per well, pretreated with 0.25 and $1 \mu \mathrm{M}$ of $\mathrm{VB}$ for $3 \mathrm{~h}$, and co-incubated with or without $10 \mu \mathrm{M}$ of $\mathrm{A} \beta_{1-42}$ at $37{ }^{\circ} \mathrm{C}$ for $12 \mathrm{~h}$. The intracellular concentrations of ROS were measured using an ROS assay kit (E004, Nanjing Jiancheng Bioengineering Institute, Nanjing, China) according to the manufacturer's instructions. The intracellular concentrations of $\mathrm{Ca}^{2+}$ were measured using Fluo-4 AM dye (F14201, Thermo Fisher Scientific, Waltham, MA, USA) according to the manufacturer's instructions. The fluorescence intensity of cells under light excitation was observed using a fluorescent inverted microscope (CKX31, Olympus, Tokyo, Japan).

\section{Measurement of apoptosis and transmission electron microscopy (TEM)}

The protocol was adjusted based on a previous study [3]. U251 cells were seeded into 6-well plates at a density of $2 \times 10^{5}$ cells per well, pretreated with $0.25 \mu \mathrm{M}$ and $1 \mu \mathrm{M}$ of $\mathrm{VB}$ for $3 \mathrm{~h}$, and then co-incubated with or without $10 \mu \mathrm{M}$ of $\mathrm{A} \beta_{1-42}$ at $37{ }^{\circ} \mathrm{C}$ for $24 \mathrm{~h}$. An Annexin V-FITC/PI Apoptosis Detection kit (Muse, Merck, Darmstadt, Germany) was used to stain the cells according to the manufacturer's instructions, and the apoptotic rates were assessed using a Muse $^{\mathrm{Tm}}$ Cell Analyzer (Muse, Merck, Darmstadt, Germany).

Treated cells were collected, fixed with $4 \%$ glutaraldehyde (R20513, ShangHai YuanYe Bio-technology co., Ltd., Shanghai, China) overnight, and post-fixed in $1 \%$ osmium tetroxide at $4{ }^{\circ} \mathrm{C}$ for $2 \mathrm{~h}$. After gradient dehydration using ethanol, acetone, and propylene oxide, cells were embedded in SPI-Pon 812 resin and cut into ultra-thin sections using an ultra-thin microtome (EM UC7, Leica Microsystems, Wetzlar, Germany). After staining with uranyl acetate and lead citrate, the morphology of mitochondria and
ER in the cells was observed by TEM (H-7650, HITACHI, Tokyo, Japan).

\section{Animals and administration}

The experiments complied with the Animal Research: Reporting In Vivo Experiments (ARRIVE) guidelines and were carried out in accordance with the National Institutes of Health guide for the care and use of laboratory animals. We obtained an ethical review regarding animal welfare, which was approved by the Experimental Animal Center of Jilin University (No. SY201905014). All of the mice were purchased from the Nanjing Biomedical Research Institute of Nanjing University, Jiangsu, China (SCXK [SU] 20150001), and raised in a room at a temperature of $23 \pm 2{ }^{\circ} \mathrm{C}$ and a humidity of 40-60\%, under a 12-h:12-h light:dark cycle and with free access to water and food.

Twenty-four B6C3-Tg (APPswePSEN1dE9)/Nju doubletransgenic male mice (genotype: (Appswe) T, (Psen1) T) (APP/PS1) (8 months old, 40.7-52.9 g) were randomly divided into two groups and given $0.4 \mathrm{~mL}$ of normal saline $(n=12)$ or $10 \mathrm{mg} / \mathrm{kg}$ of VB $(n=12)$ orally for 42 days. An additional 12 wild-type (WT) male mice (genotype: (Appswe) W, (Psen1) W) (8 months old, 41.4-51.9 g) were treated orally with $0.4 \mathrm{~mL}$ of normal saline each day for 42 days. Behavioral training was started after 30 days of VB administration. After the entire 42-day VB treatment period, all of the mice were euthanized via intraperitoneal injection of sodium pentobarbital $(150 \mathrm{mg} / \mathrm{kg})$. Sera and organs, comprising the brain, kidney, spleen, and liver, were quickly collected. Brain, liver, spleen, and kidney tissues of mice from each group were fixed in $4 \%$ paraformaldehyde $(n=$ 3 /group), and the remaining tissues were immediately stored at $-140{ }^{\circ} \mathrm{C}$ for testing $(n=9$ /group). The experimental schedule is shown in Fig. 1.

\section{Behavioral tests \\ Open-field test (OFT)}

The experimental procedure was modified based on a previously reported approach [34]. On the 31st day, an OFT was performed of all experimental mice in each group ( $n=12$ /group) (Fig. 1 ). The open-field device was $50 \times 50 \mathrm{~cm}$ and divided into a central area of $25 \times 25$ $\mathrm{cm}$ and a surrounding area (ZS_ZFT;ZS DiChuang Technology Development Co., Ltd., Beijing, China). In the formal test, each mouse was placed into the open field at the same location. The trajectory of mice, their total distance moved, and the time spent in the central area were recorded by camera for $5 \mathrm{~min}$ and analyzed using ANY-maze ${ }^{\mathrm{TM}}$ video-tracking software (Stoelting Co., Chicago, IL, USA). The OFT apparatus was cleaned before testing each mouse to ensure that no information from prior tests was present. 


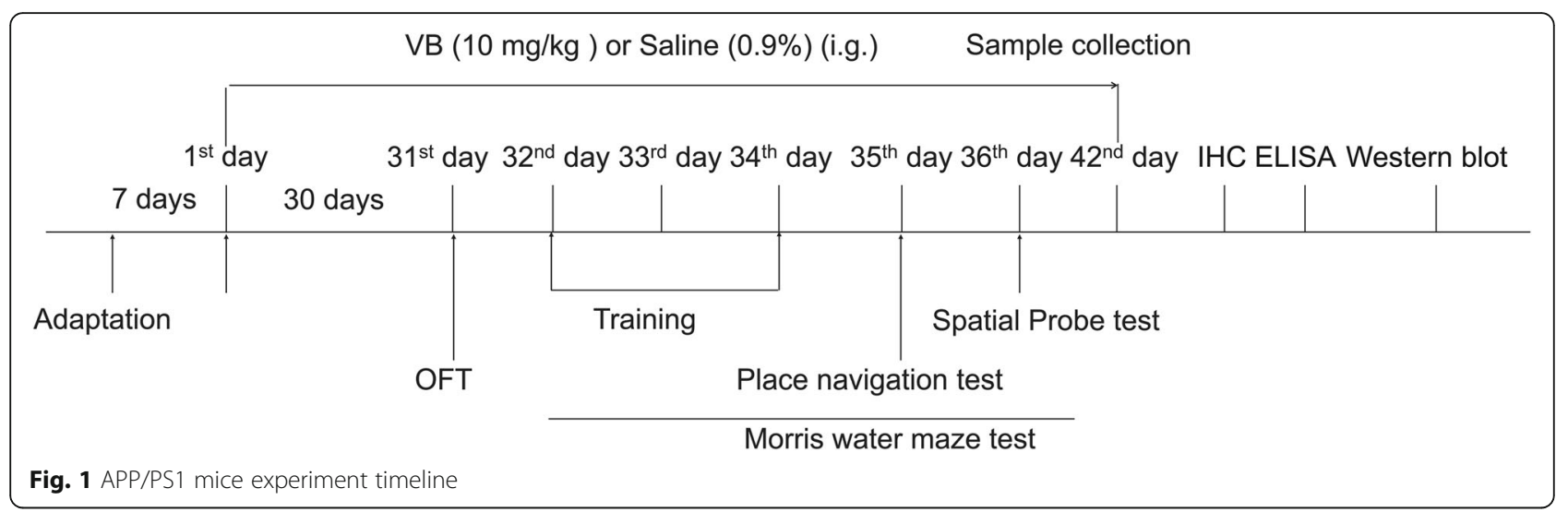

\section{Morris water maze (MWM) test}

The protocol was adjusted based on a previously reported method [35]. An MT-200 Water Labyrinth Video Tracking Analysis System (MT-200) (TECHMAN Software Co., Ltd., Chengdu, China) with a 100-cm-diameter pool was used for MWM tests of all of the experimental mice ( $n=12 /$ group). The circular pool was filled to a 40 -cm depth with water $\left(24 \pm 2{ }^{\circ} \mathrm{C}\right)$ containing titanium dioxide. The water level was $0.5 \mathrm{~cm}$ higher than the height of the platform. From the 32nd day, the mice were trained four times per day for 3 days. During the training process, the mice were placed on the platform for $15 \mathrm{~s}$ and then put into the maze facing the wall at the position furthest from the platform. Mice were then allowed $60 \mathrm{~s}$ to find the platform. The swimming speed of each mouse and the time it took to find the platform were recorded. The mice that failed to find the platform were manually placed on the platform for $15 \mathrm{~s}$. The place navigation test was executed on the 35th day. Each mouse was placed in the maze at the same location as during training. The movement trajectory, time spent searching for the platform, and swimming speed of all mice were recorded using a camera over $60 \mathrm{~s}$. If a mouse did not find the platform within $60 \mathrm{~s}$, its search time was recorded as $60 \mathrm{~s}$. A spatial probe test was conducted on the 36th day (Fig. 1). On the same day, the platform was taken away, and the mice were again put into the maze at the same position as before. The movement trajectory of mice, the number of times the mice crossed the previous location of the platform, and the time that mice spent in the effective area were recorded using a camera over 60 s. All of the data were analyzed using Watermaze2.0 software (TECHMAN Software Co., Ltd., Chengdu, China).

\section{Hematoxylin and eosin (H\&E) staining}

As described in our previous research [36], brain, liver, spleen, and kidney tissues were fixed in $4 \%$ paraformaldehyde, embedded in paraffin, cut to a thickness of $5 \mu \mathrm{m}$, and stained with H\&E. The sections $(n=3$ /group) were observed using an optical microscope (BX51, Olympus, Tokyo, Japan).

\section{Terminal deoxynucleotidyl transferase-mediated deoxyuridine triphosphate nick end labeling (TUNEL) and thioflavin-S staining}

As in our previous study [37], the paraffin-embedded brain sections were soaked in xylene, treated with an ethanol gradient (100\%, 90\%, 80\%, 70\%), and incubated with terminal deoxynucleotidyl transferase and Click-i ${ }^{\mathrm{mu}}$ Plus (Catalog Nos. C10617, Invitrogen, Thermo Fisher Scientific, Waltham, MA, USA) according to the instructions supplied by the manufacturer for TUNEL staining. For thioflavin-S staining, ethanol gradient-treated sections were stained with $0.3 \%$ thioflavin-S at $25{ }^{\circ} \mathrm{C}$ for 8 min and then washed with $50 \%$ ethanol. All of the sections ( $n=3$ /group) were observed using a fluorescence microscope (BX53, Olympus, Tokyo, Japan).

\section{Immunohistochemical analyses}

Similar to our previous protocol [33], the paraffinembedded brain sections were soaked in xylene, treated with an ethanol gradient $(95 \%, 85 \%, 75 \%)$, blocked with $3 \% \mathrm{H}_{2} \mathrm{O}_{2}$ for $10 \mathrm{~min}$, sealed with $10 \%$ goat serum (Bioss, Beijing, China) for $30 \mathrm{~min}$, and incubated with primary antibodies for $A \beta_{1-42}$, tau (phosphor S396), 4hydroxynonenal (4-HNE), and mesencephalic astrocytederived neurotrophic factor (MANF) at $4{ }^{\circ} \mathrm{C}$ overnight. The sections were incubated with goat anti-rabbit IgG $(\mathrm{H}+\mathrm{L})$ (peroxidase/HRP conjugated) and subjected to $5 \%$ diaminobenzidine oxidation. After staining with DAB (Solarbio, Beijing, China), the sections $(n=3$ /group) were observed using an optical microscope (BX51, Olympus, Tokyo, Japan). The details of the above antibodies are presented in Table 1.

\section{Label-free quantification proteomics}

Similar to a previously reported study [38], the brain samples ( $n=6$ /group) were lysed using radio-immunoprecipitation assay (RIPA) buffer containing phenylmethanesulfonylfluoride 
Table 1 Details of antibodies used in immunohistochemical and western blot

\begin{tabular}{|c|c|c|c|c|c|c|c|}
\hline Number & Antibodies & $\begin{array}{l}\text { Molecular } \\
\text { weight }\end{array}$ & $\begin{array}{l}\text { Catalog } \\
\text { number }\end{array}$ & Dilution & Application & Company & Area \\
\hline 1 & $A \beta_{1-42}$ & & bs-0107R & $1: 800$ & Immunohistochemical & Bioss & Beijing, China \\
\hline 2 & 4-HNE & & ab46545 & 1:200 & Immunohistochemical & Abcam & Cambridge, MA, USA \\
\hline 3 & tau (phosphor S396) & & ab109390 & $1: 4000$ & Immunohistochemical & Abcam & Cambridge, MA, USA \\
\hline 4 & MANF & & ab67271 & $1: 400$ & Immunohistochemical & Abcam & Cambridge, MA, USA \\
\hline 5 & MANF & $20 \mathrm{kDa}$ & ab67271 & $1: 1000$ & Western blot & Abcam & Cambridge, MA, USA \\
\hline 6 & $\mathrm{BiP}$ & $78 \mathrm{kDa}$ & ab21685 & 1:250 & Western blot & Abcam & Cambridge, MA, USA \\
\hline 7 & p-IRE1 phosphor S724 & 110 kDa & ab48187 & $1: 1000$ & Western blot & Abcam & Cambridge, MA, USA \\
\hline 8 & $\mathrm{CHOP}$ & $27 \mathrm{kDa}$ & ab11419 & $1: 1000$ & Western blot & Abcam & Cambridge, MA, USA \\
\hline 9 & IRE1 & 105 kDa & BS-8680R & $1: 1000$ & Western blot & Bioss & Beijing, China \\
\hline \multirow[t]{2}{*}{10} & XBP1 & $40 \mathrm{kDa}$ & bs-1668R & $1: 1000$ & Western blot & Bioss & Beijing, China \\
\hline & PERK & 122 kDa & BSM-51385M & $1: 1000$ & Western blot & Bioss & Beijing, China \\
\hline 11 & ATF6 & $75 \mathrm{kDa}$ & bs-1634R & 1:500 & Western blot & Bioss & Beijing, China \\
\hline 12 & ATF4 & $38 \mathrm{kDa}$ & bs-1531R & $1: 5000$ & Western blot & Bioss & Beijing, China \\
\hline 13 & p-PERK (Thr982) & $125 \mathrm{kDa}$ & DF7576 & $1: 800$ & Western blot & Affinity Biosciences & Cincinnati, OH, USA \\
\hline 14 & elF2a & $38 \mathrm{kDa}$ & 97225 & 1:1000 & Western blot & Cell Signaling Technology & Beverly, MA, USA \\
\hline 15 & p-elF2a (Ser51) & $38 \mathrm{kDa}$ & $9721 S$ & $1: 1000$ & Western blot & Cell Signaling Technology & Beverly, MA, USA \\
\hline 16 & caspase12 & $38 \mathrm{kDa}$ & $\mathrm{A} 0217$ & 1:1000 & Western blot & ABclonal & Wuhan, China \\
\hline 17 & GAPDH & $37 \mathrm{kDa}$ & E-AB-20059 & $1: 2000$ & Western blot & Elabscience & Wuhan, China \\
\hline 18 & Goat anti-mouse & & E-AB-1001 & $1: 5000$ & Western blot & Elabscience & Wuhan, China \\
\hline 19 & Goat anti-rabbit & & E-AB-1003 & $1: 5000$ & Western blot & Elabscience & Wuhan, China \\
\hline
\end{tabular}

(PMSF), stored on ice, and quantified using a Pierce ${ }^{\text {TM }}$ BCA Protein Assay Kit (23225, Thermo Scientific, Waltham, MA, USA). After the protein was precipitated with pre-cooled acetone, ammonium bicarbonate (containing 1\% sodium deoxycholate), tris-(2-carboxyethyl)-phosphine, iodoacetamide, and trypsin were successively added to the protein. Trifluoroacetic acid was added to remove sodium deoxycholate from the protein. After desalting, the samples were analyzed using liquid chromatography-tandem mass spectrometry (LC-MS/MS). For each sample, approximately 2 $\mu \mathrm{g}$ of peptide were isolated and analyzed with nano ultra-performance liquid chromatography (EASY-nLC1200) coupled to Q-Exactive mass spectrometry (Thermo Finnigan). Chromatographic separation was performed on a reverse-phase column $(100 \mu \mathrm{m}$, ID $\times 15 \mathrm{~cm}$, Reprosil-Pur 120 C18-AQ, $1.9 \mu \mathrm{m}$, Dr. Math). Statistical analysis was performed on the standardized quantitative results to obtain the corresponding differentially expressed proteins. Raw MS files were processed with MaxQuant (Version 1.5.6.0). The protein sequence database was downloaded from UniProt. Proteins that were significantly differentially expressed were used to perform clustering analysis and presented as a heatmap. Protein interaction analysis was performed using the STRING database. All of the above reagents were purchased from Sigma-Aldrich (St. Louis, MO, USA).

\section{Elisa}

The brain tissue samples ( $n=8$ /group) were lysed with RIPA buffer containing PMSF and stored on ice. The collected protein samples were quantified using a Pierce ${ }^{\text {тм }}$ BCA Assay Kit. The concentrations of the following proteins were analyzed using the corresponding commercial ELISA kits (Jiangsu Kete Biological Technology Co., Ltd, Jiangsu, China): caspase 3 (F9179-A), caspase 12 (KT9236A), caspase 8 (KT9229-A), insulin-degrading enzyme (IDE) (KT9252-A), ROS (KT2800-A), X-box binding protein 1 (XBP1) (KT9259-A), inositol requiring protein 1 (IRE1) (KT9244-A), activating transcription factor-6 (ATF6) (KT9235-A), MANF (KT9262-A), C/EBP-homologous protein (CHOP) (KT9231-A), pancreatic ER kinase (PERK) (KT9250-A), A $\beta_{1-42}$ (KT9256-A), BiP (KT9240-A), eukaryotic initiation factor 2 (eIF2 $\alpha$ ) (KT9439-A), activating transcription factor-4 (ATF4) (KT9373-A), phosphorylated (p)-eIF2 $\alpha$ (KT9422-A), p-PERK (KT9413-A), and p-IRE1 (KT9432-A). The absorbance at $450 \mathrm{~nm}$ was detected using a microplate reader (Synergy 4, Omega BioTek, Inc., Norcross, GA, USA).

\section{Western blot}

U251 cells were seeded into 6-well plates at a density of $2 \times 10^{5}$ cells per well, pretreated with 0.25 and $1 \mu \mathrm{M}$ of $\mathrm{VB}$ for $3 \mathrm{~h}$, and then co-incubated with or without $10 \mu \mathrm{M}$ 
of $\mathrm{A} \beta_{1-42}$ at $37{ }^{\circ} \mathrm{C}$ for $24 \mathrm{~h}$. The brain tissues collected from experimental mice and treated cells were lysed using RIPA buffer containing PMSF, stored on ice, and quantified using the Pierce ${ }^{\text {tm }}$ BCA Protein Assay Kit. Samples in each group contained brain tissues from three mice.

As in our previous study [39], $40 \mu \mathrm{g}$ of protein and 4 $\mu \mathrm{L}$ of marker (26616, Thermo scientific, Waltham, MA, USA) were separated using sodium dodecyl sulfatepolyacrylamide gel electrophoresis and then transferred to polyvinylidene fluoride membranes $(0.45 \mu \mathrm{m})$ (GE Healthcare Life Science, Beijing, China). The loaded membranes were blocked in $5 \%$ bovine serum albumin at $4{ }^{\circ} \mathrm{C}$ for $5 \mathrm{~h}$ and then incubated separately with the following primary antibodies at $4{ }^{\circ} \mathrm{C}$ overnight: MANF, BiP, p-IRE1 (phosphor S724), CHOP, ATF6, IRE1, XBP1, PERK, ATF4, p-PERK (Thr982), eIF2 $\alpha, \mathrm{p}$-eIF2 $\alpha$, caspase12, and glyceraldehyde 3-phosphate dehydrogenase (GAPDH). After washing with tris-buffered saline containing $0.1 \%$ Tween 20 , the membranes were incubated separately with the following secondary antibodies: goat anti-mouse IgG $(\mathrm{H}+\mathrm{L})$ (peroxidase/HRP conjugated) and goat anti-rabbit IgG $(\mathrm{H}+\mathrm{L})$ (peroxidase/HRP conjugated). The membranes were then exposed using an electrochemiluminescence kit (Merck, Darmstadt, Germany) to obtain blots, which were visualized using an automatic chemiluminescence image analysis system (Tanon 5200, Tanon Science \& Technology Co., Ltd., Shanghai, China) and quantified using Image-pro Plus 6.0 analysis software (Media Cybernetics, Bethesda, MD, USA). The details of the above antibodies are presented in Table 1.

\section{Statistical analysis}

Data were expressed as means \pm standard errors of the mean (SEM). Statistical significance was determined using one-way analysis of variance with SPSS 16.0 software (IBM Corp., Armonk, NY, USA). Post hoc analysis was performed using multiple comparisons (Dunn's test). A $p$ value $<0.05$ was considered to indicate a statistically significant difference. All of the graphs were produced using GraphPad Prism 7.0 (GraphPad Software Inc., San Diego, CA, USA).

\section{Results}

Neuroprotective effects of $V B$ against $A \beta_{1-42}$-induced neurotoxicity in U251 cells

VB enhanced the cell viability of $A \beta_{1-42}$-exposed U251 cells at a concentration of 0.25 and $1 \mu \mathrm{M}(p<0.05)$, but showed no significant effects on cell viability in normal U251 cells (Fig. 2a). VB reduced the apoptosis rate by greater than $10.79 \%$ (Fig. 2b), strongly inhibited intracellular $\mathrm{Ca}^{2+}$ flux (Fig. 2c), and suppressed the overaccumulation of ROS (Fig. 2d) in $A \beta_{1-42}$-exposed U251 cells. TEM showed that expansion of the perinuclear space, expansion and partial degranulation of rough ER, and increased mitochondrial electron density were visible in $A \beta_{1-42}$-incubated U251 cells, and these effects were partially reversed by VB treatment (Fig. 2e).

\section{VB improves memory and spatial cognition in APP/PS1 mice due to its suppression of $A \beta$ deposition and tau protein accumulation}

Healthy mice prefer to remain on the periphery of the open field, whereas mice with cognitive impairment explore the central area [40]. APP/PS1 mice spent more time in the central area than did WT mice $(p<0.001)$. The abnormal behaviors were decreased after VB administration $(p<0.001)($ Fig. 3a-c). MWM tests are commonly used to study the spatial learning and memory of animals [3]. VB improved spatial cognition, learning, and memory ability, as suggested by the obvious decrease in the escape-latency time of APP/PS1 mice on the 35th day with no significant change in swimming speed in the MWM test $(p<0.01)$ (Fig. $3 \mathrm{~d}-\mathrm{f})$. This was also shown by the obvious increase in the number of times the VB mice crossed the previous location of the platform, and the increase in the time that mice spent in the effective area on the 36th day $(p<$ 0.01) (Fig. 3g-i).

VB reduced apoptosis in the cortex and hippocampus of APP/PS1 mice (Fig. 4a). Senile plaques formed by the aggregation and deposition of $\mathrm{A} \beta_{1-42}$ and NFTs formed by the over-expression of phosphorylated tau protein are the two pathological signs of $\mathrm{AD}$ [7]. Compared with vehicle-treated APP/PS1 mice, VB-treated mice had reduced expression levels of $A \beta$ in the hippocampus (Fig. $4 b, c)$, lowered concentrations of $A \beta_{1-42}$ in brain lysates $(p<0.001)$ (Fig. 4d), and increased concentrations of $\mathrm{A} \beta_{1-42}$ in serum $(p<0.05)$ (Fig. $\left.4 \mathrm{~d}\right)$. VB suppressed the elevated concentrations of phosphorylated tau protein in the brains of APP/PS1 mice (Fig. 4e). 4-HNE, a neurotoxicity product of lipid peroxidation, is highly expressed in the brain and cerebrospinal fluid of $\mathrm{AD}$ patients [41]. The concentrations of 4-HNE in the hippocampus of APP/PS1 mice were substantially reduced by VB administration (Fig. 4f). MANF is a key factor in alleviating ER stress and maintaining ER homeostasis [42] and has been confirmed to be upregulated during ER stress and can resist $A \beta$ toxicity by attenuating $A \beta$-induced $E R$ stress [43]. In the hippocampus of APP/PS1 mice, VB decreased the expression levels of MANF, suggesting that VB protected against ER stress (Fig. 4g).

No significant changes in body weight (Additional file 1: Fig. S2) or pathologic changes in the brain (Fig. 4h), spleen (Additional file 1: Fig. S3A), liver (Additional file 1: Fig. S3B), or kidney (Additional file 1: Fig. S3C) of experimental mice were noted. 


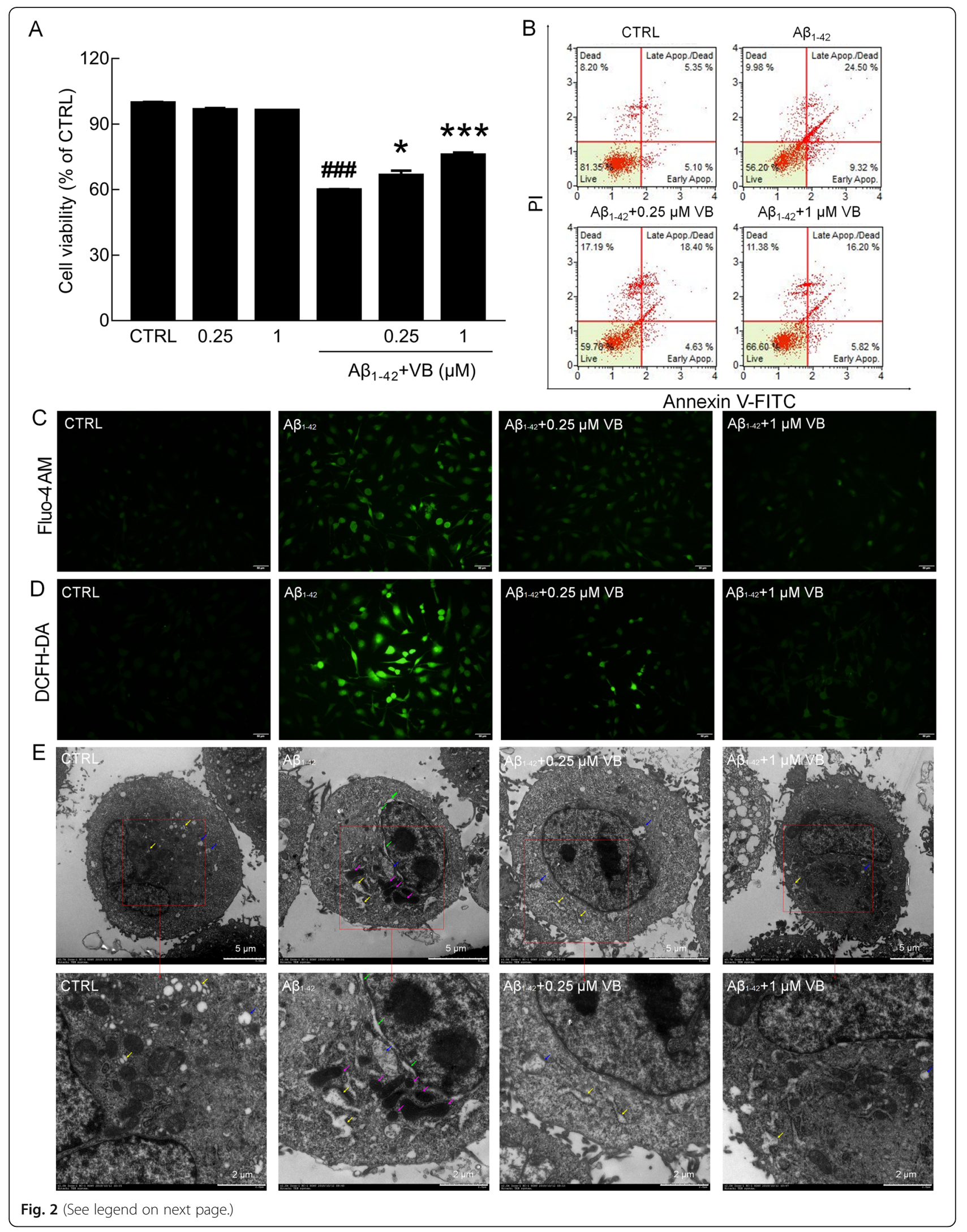


(See figure on previous page.)

Fig. 2 VB attenuated $A \beta_{1-42}$-induced $U 251$ cell apoptosis. a VB increased cell viability that had been reduced by $A \beta_{1-42}$ exposure, but failed to improve cell viability alone $\left(n=6 /\right.$ group). The data are presented as mean \pm SEM. ${ }^{\# \# \#} p<0.001 \mathrm{Vs}$. CTRL, and ${ }^{*} p<0.05,{ }^{* * *} p<0.001 \mathrm{Vs}$. A $\beta_{1-42^{-}}$ exposed U251 cells. $\mathbf{b} \vee B$ reduced the apoptotic rate of $A \beta_{1-42}$-exposed U251 cells ( $n=4 /$ group). c Fluorescence microscopy showed that VB suppressed the $\mathrm{Ca}^{2+}$ flux caused by $A \beta_{1-42}$ (scale bar: $50 \mu \mathrm{m}$, magnification $\left.\times 20\right)(n=4 / g r o u p)$. $\mathbf{d}$ Fluorescence microscopy showed that VB suppressed the over-accumulation of intracellular reactive oxygen species (scale bar: $50 \mu \mathrm{m}$, magnification $\times 20)(n=4 / g r o u p)$. e TEM analysis showed that VB improved ER and mitochondrial morphology. The expansion of ER was marked by yellow arrows, the mitochondrial cavitation was marked by blue arrows, the mitochondrial electron density increase was marked by pink arrows, and the space around the nucleus was marked by green arrows (scale bar $5 \mu \mathrm{m}$, magnification $\times 0.7 \mathrm{k}$ ) (scale bar $5 \mu \mathrm{m}$, magnification $\times 1.0 \mathrm{k}$ ) (scale bar $2 \mu \mathrm{m}$, magnification $\times$ 2.0 k) ( $n=4 /$ group)

\section{The protective effect of $V B$ against $A D$ is related to its regulation of ER stress}

LC-MS/MS was used to separate and analyze the peptides in the hippocampus of APP/PS1 mice. The data were processed with MaxQuant and label-free quantification, with matching between run and intensitybased absolute quantification, and proteins with a ratio of $\mathrm{A} / \mathrm{B}>1.5$ or $<0.66$ were defined as significantly differentially expressed (where A and B represent the expression level of any protein in two groups). Proteins showing significant differences in expression between APP/PS1 mice and WT mice and between $\mathrm{APP} / \mathrm{PS} 1+\mathrm{VB}$ mice and APP/PS1 mice were used to perform clustering analysis. Compared with non-treated APP/PS1 mice, VB-treated mice had increased concentrations of 19 proteins and decreased concentrations of 7 proteins (Fig. 5a) (Table 2).

STRING is a database of known and predicted proteinprotein interactions. In this study, the interactions of 43 proteins among experimental groups were analyzed. Protein-protein interaction results showed that VB had a significant effect on ER-related factors (Fig. 5b).

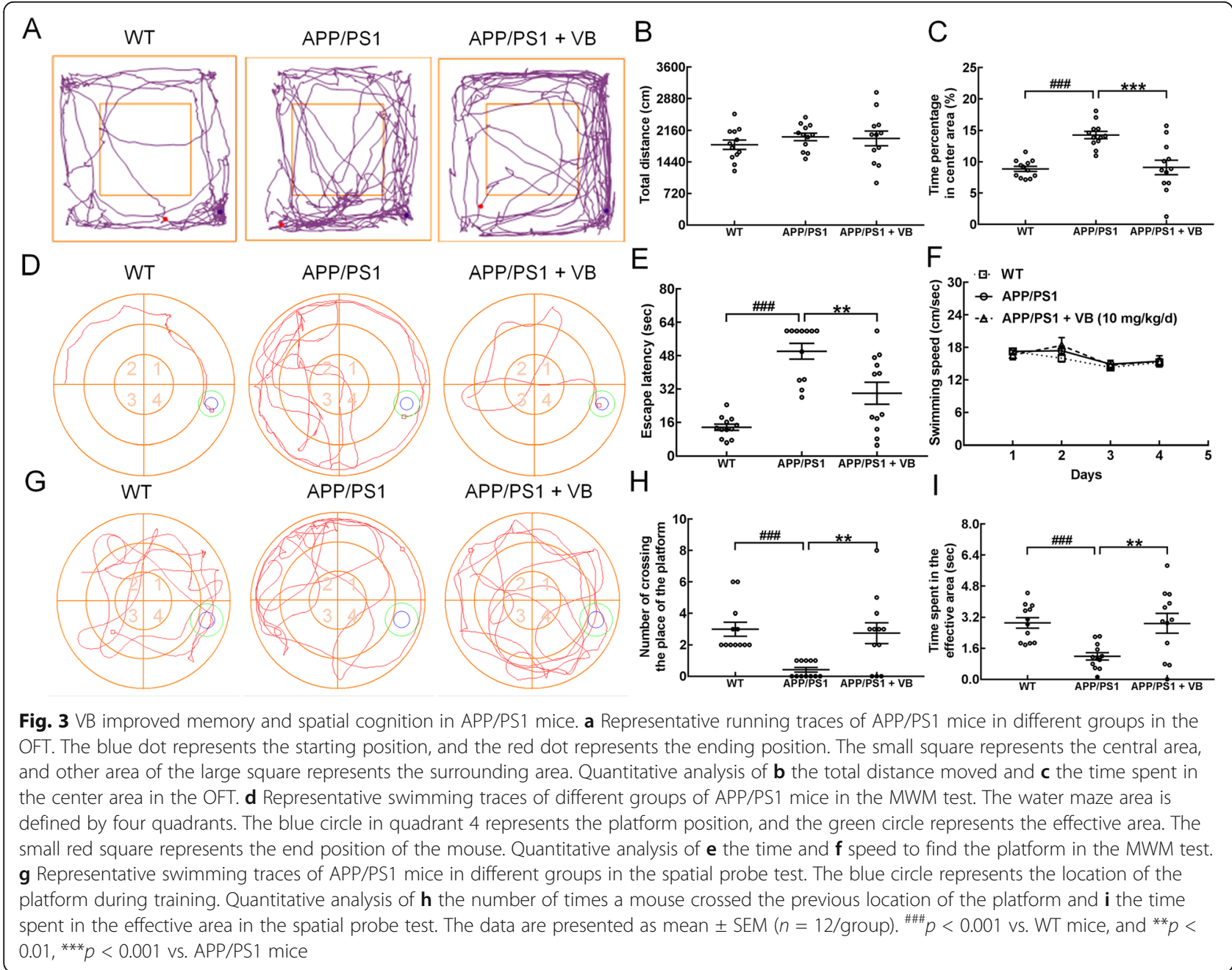




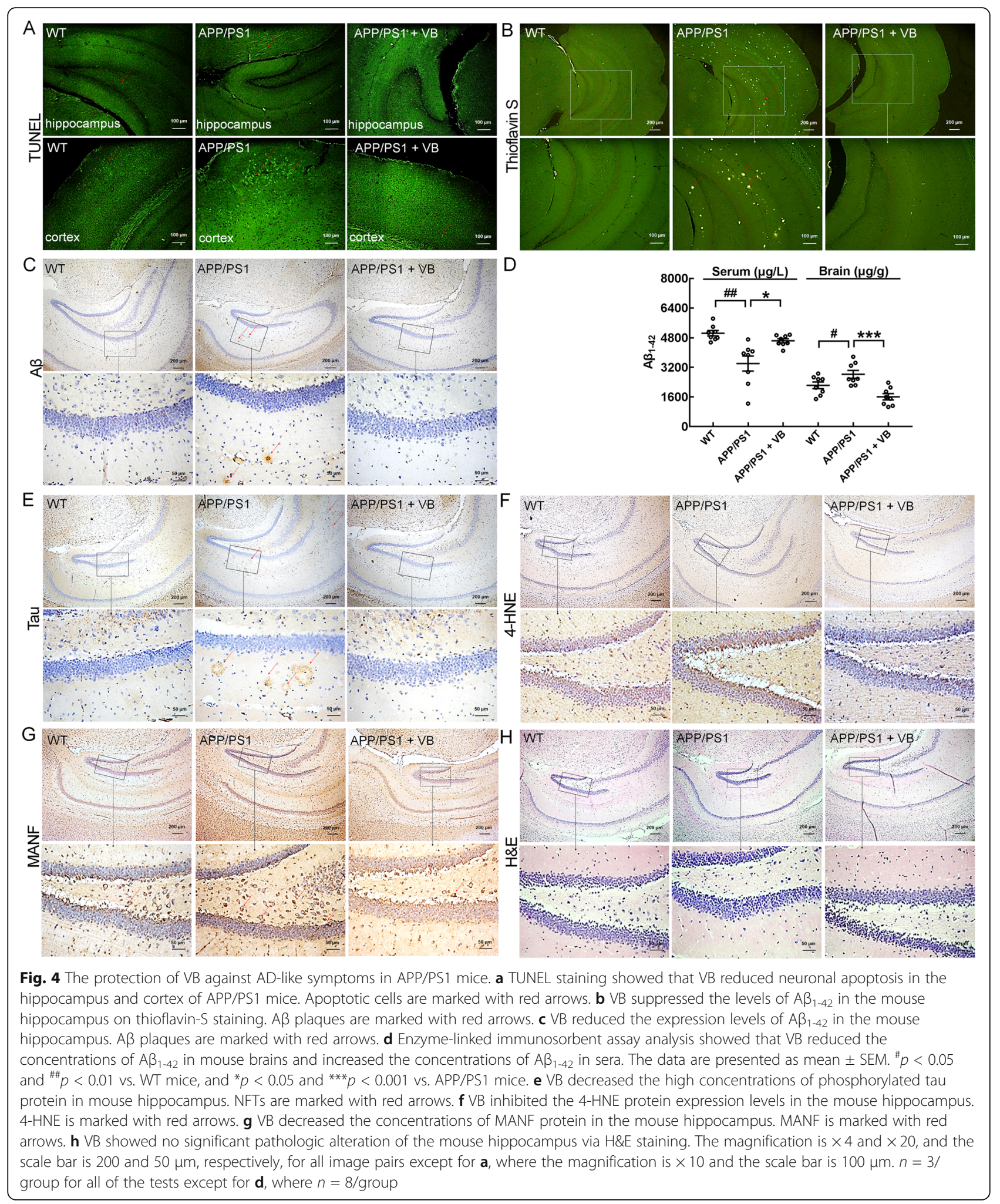

Excessive accumulation of $A \beta$ and tau protein can cause abnormal ER stress, which in turn promotes $A D$ [5]. According to proteomic screening and analysis, 10 proteins related to ER stress were further confirmed in this experiment via ELISA. Encouragingly, VB was effective in alleviating ER stress, as suggested by its reduction in the concentrations of MANF (an ER resident protein that regulates ER homeostasis in neurons [44]) 


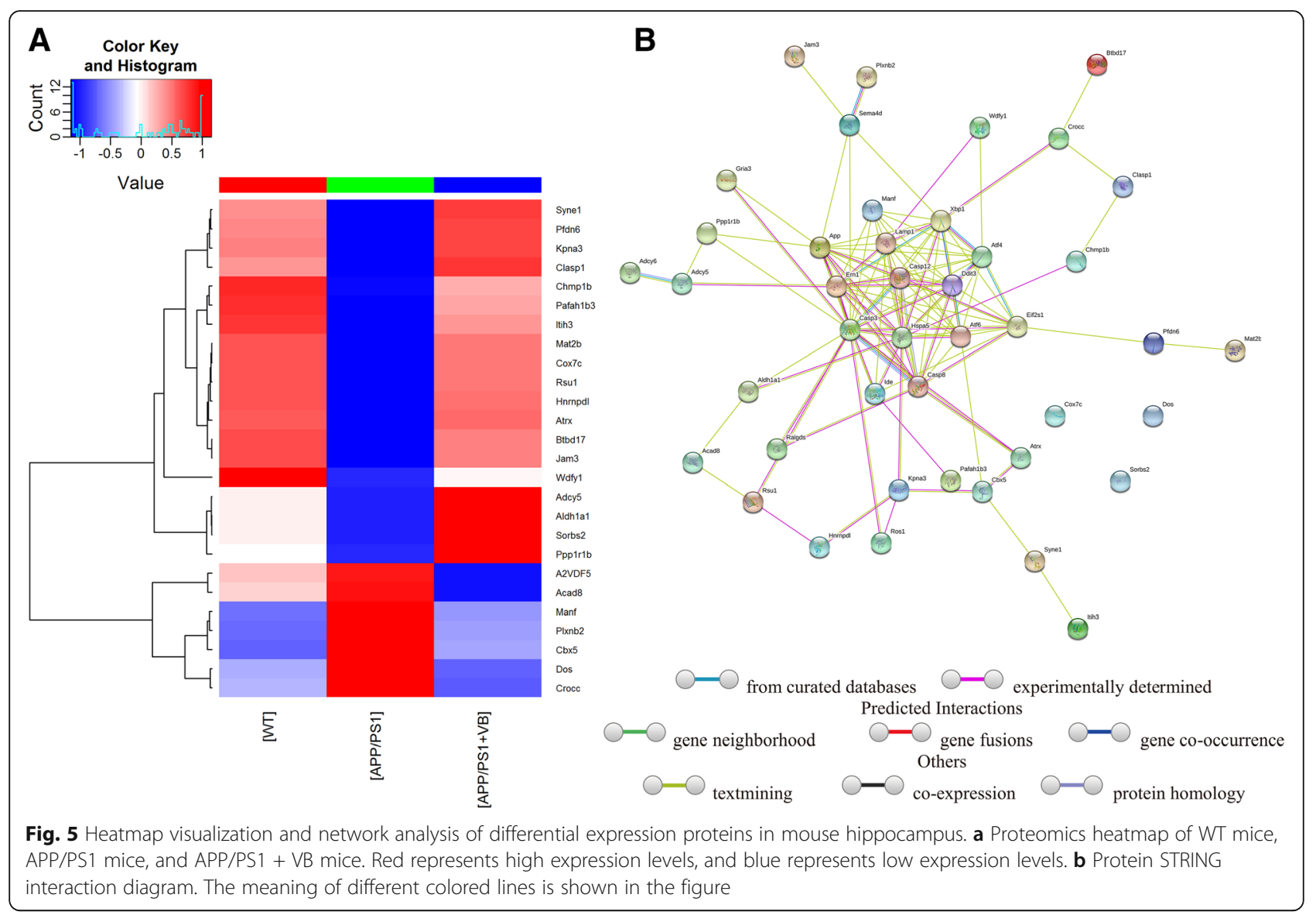

$(p<0.001)$ (Fig. 6a), BiP (an ER chaperone that regulates the homeostasis of protein folding [45]) $(p<0.05)$ (Fig. 6b), ATF6 (an ER transmembrane receptor related to ER stress [46]) $(p<0.05)$ (Fig. 6c), p-IRE1/IRE1 (an ERlocated kinase that mediates both adaptive and proapoptotic programs under ER stress [47]) $(p<0.05)$ (Fig. 6d), XBP1 (a transcription factor that activates the UPR target gene cluster [47]) $(p<0.05)$ (Fig. 6e), phosphorylated protein kinase-like endoplasmic reticulum kinase (pPERK)/PERK (a type I transmembrane kinase that is positioned at the ER membrane to regulate ER stress [5]) $(p<0.05)$ (Fig. 6f), p-eIF2 $\alpha /$ eIF2 $\alpha$ (a kinase related to cognitive disorders and memory impairment due to its over-activation [48]) $(p<0.05)$ (Fig. 6g), ATF4 (a transcription factor that controls protein folding and redox homeostasis in the ER [5]) $(p<0.05)$ (Fig. 6h), CHOP (an important mediator of ER stress-induced cell arrest and apoptosis [49]) $(p<0.05)$ (Fig. 6i), and caspase12 (an ER resident pro-caspase that is activated under ER stress [50]) $(p<0.001)$ (Fig. 6j) in the brains of APP/PS1 mice.

Proteins related to apoptosis and oxidative stress were also detected. Compared with vehicle-treated APP/PS1 mice, VB-treated mice had reduced concentrations of caspase 3 (which promotes the release of cytochrome c from mitochondria and the collapse of membrane potential [51]) $(p<0.001)$ (Additional file 1: Fig. S4A), caspase 8 (which initiates the apoptotic pathway in mitochondria [52]) $(p<0.001)$ (Additional file 1: Fig. S4B) and ROS (which are species that are directly responsible for oxidative stress [53]) $(p<0.001)$ (Additional file 1: Fig. S4C), and increased the concentrations of IDE (an important enzyme responsible for the degradation and clearance of $A \beta$ [54]) $(p<0.05)$ (Additional file 1: Fig. S4D) in the brains of APP/PS1 mice. These findings support the protective effects of $\mathrm{VB}$ against apoptosis in $\mathrm{AD}$.

\section{VB regulated the expressions of protein related to ER stress}

In the brain lysates of APP/PS1 mice and $A \beta_{1-42}$-exposed U251 cells, VB reduced the concentrations of MANF $(p<0.01), \operatorname{BiP}(p<0.05), \operatorname{ATF} 6(p<0.05), \mathrm{p}-\mathrm{IRE} 1 /$ IRE1 $(p<0.05)$, XBP1 $(p<0.05)$, p-PERK/PERK $(p<$ $0.05)$, p-eIF2 $\alpha /$ eIF $2 \alpha(p<0.05)$, ATF4 $(p<0.05)$, CHOP $(p<0.05)$, and Caspase12 $(p<0.01)$ (Fig. 7a, b).

\section{Discussion}

In the present study, we found VB attenuates AD symptoms and pathology and decreases ER stress in mice models and cultured cells. These findings, for the first 
Table 2 Proteins with significantly different expression levels in proteomics

\begin{tabular}{|c|c|c|c|c|}
\hline Number & Gene names & Unique peptides & fc. APP/PS1-WT & $\begin{array}{l}\text { fc. APP/PS1 + VB } \\
\text {-APP/PS1 }\end{array}$ \\
\hline \multicolumn{5}{|c|}{ Upregulated proteins by VB (number: 19) } \\
\hline 1 & Syne1 & 7 & 0.21 & 7.12 \\
\hline 2 & Pfdn6 & 2 & 0.17 & 4.01 \\
\hline 3 & Kpna3 & 4 & 0.10 & 4.15 \\
\hline 4 & Clasp1 & 8 & 0.02 & 71.45 \\
\hline 5 & Chmp1b & 2 & 0.63 & 1.50 \\
\hline 6 & Pafah1b3 & 3 & 0.14 & 3.35 \\
\hline 7 & Itih3 & 5 & 0.14 & 1.83 \\
\hline 8 & Mat2b & 5 & 0.12 & 6.65 \\
\hline 9 & Cox7c & 2 & 0.12 & 45.81 \\
\hline 10 & Rsu1 & 2 & 0.21 & 3.93 \\
\hline 11 & Hnrnpdl & 5 & 0.05 & 15.48 \\
\hline 12 & Atrx & 3 & 0.03 & 32.42 \\
\hline 13 & Btbd17 & 8 & 0.45 & 2.07 \\
\hline 14 & Jam3 & 4 & 0.14 & 3.84 \\
\hline 15 & Wdfy 1 & 6 & 0.46 & 1.53 \\
\hline 16 & Adcy5 & 13 & 0.50 & 3.01 \\
\hline 17 & Aldh1a1 & 10 & 0.72 & 1.79 \\
\hline 18 & Sorbs2 & 8 & 0.18 & 7.46 \\
\hline 19 & Ppp1r1b & 9 & 0.55 & 2.85 \\
\hline \multicolumn{5}{|c|}{ Downregulated proteins by VB (number: 7) } \\
\hline 1 & A2VDF5 & 2 & 1.50 & 0.12 \\
\hline 2 & Acad8 & 5 & 1.59 & 0.09 \\
\hline 3 & Manf & 4 & 5.54 & 0.26 \\
\hline 4 & Plxnb2 & 6 & 5.55 & 0.28 \\
\hline 5 & Cbx5 & 3 & 6.23 & 0.29 \\
\hline 6 & Dos & 3 & 2.99 & 0.19 \\
\hline 7 & Crocc & 4 & 3.64 & 0.10 \\
\hline
\end{tabular}

fc. APP/PS1-WT: the ratio of protein between saline-treated APP/PS1mice and WT mice; fc. APP/PS1 + VB-APP/PS1: the ratio of protein between VB-treated APP/ PS1mice and saline-treated APP/PS1mice

time, prove $\mathrm{VB}$ inhibits the progression of $\mathrm{AD}$ via modulating ER stress in the central nervous system, suggesting $\mathrm{VB}$ is a potential therapeutic medicine in the future. These findings also support the hypothesis that ER stress mediates the progression of $\mathrm{AD}[23]$.

Here, we demonstrated that in $A \beta_{1-42}$-damaged U251 cells, VB increased viability and reduced the concentrations of intracellular $\mathrm{Ca}^{2+}$ and $\mathrm{ROS}$ in vitro. In the early stages of $\mathrm{AD}$, mitochondrial damage causes intracellular ROS accumulation [55], eventually leading to mitochondrial dysfunction [56]. This promotes $A \beta$ accumulation [57] and induces ER stress leading to hyper phosphorylation of tau protein $[26,43] . A \beta_{1-42}$ treatment has been reported to change the morphology of astrocytes and regulates the release of interleukin-1 beta and tumor necrosis factor alpha by activating
PERK/elF2 $\alpha$-dependent ER stress, which induces neuroinflammation and apoptosis [27]. Notably, VB significantly improved the morphological characteristics of mitochondria and ER in U251 cells. These data are consistent with previous reports $[16,22,58]$ and confirmed the neuroprotective activity of $\mathrm{VB}$ in vitro.

As the commonly used mouse model of AD, the APP/ PS1 double-transgenic mouse displays over-expression of amyloid precursor protein (APP) and presenilin 1 and decreasing memory ability with age [59]. In the 9month-old APP/PS1 mouse, VB reduced anxiety, improved memory and spatial cognition, suppressed the deposition of $A \beta$ and tau protein phosphorylation, and decreased the overexpression of 4-HNE and MANF in the hippocampus. Excessive accumulation of $A \beta$ and increased phosphorylation of tau protein can trigger ER 


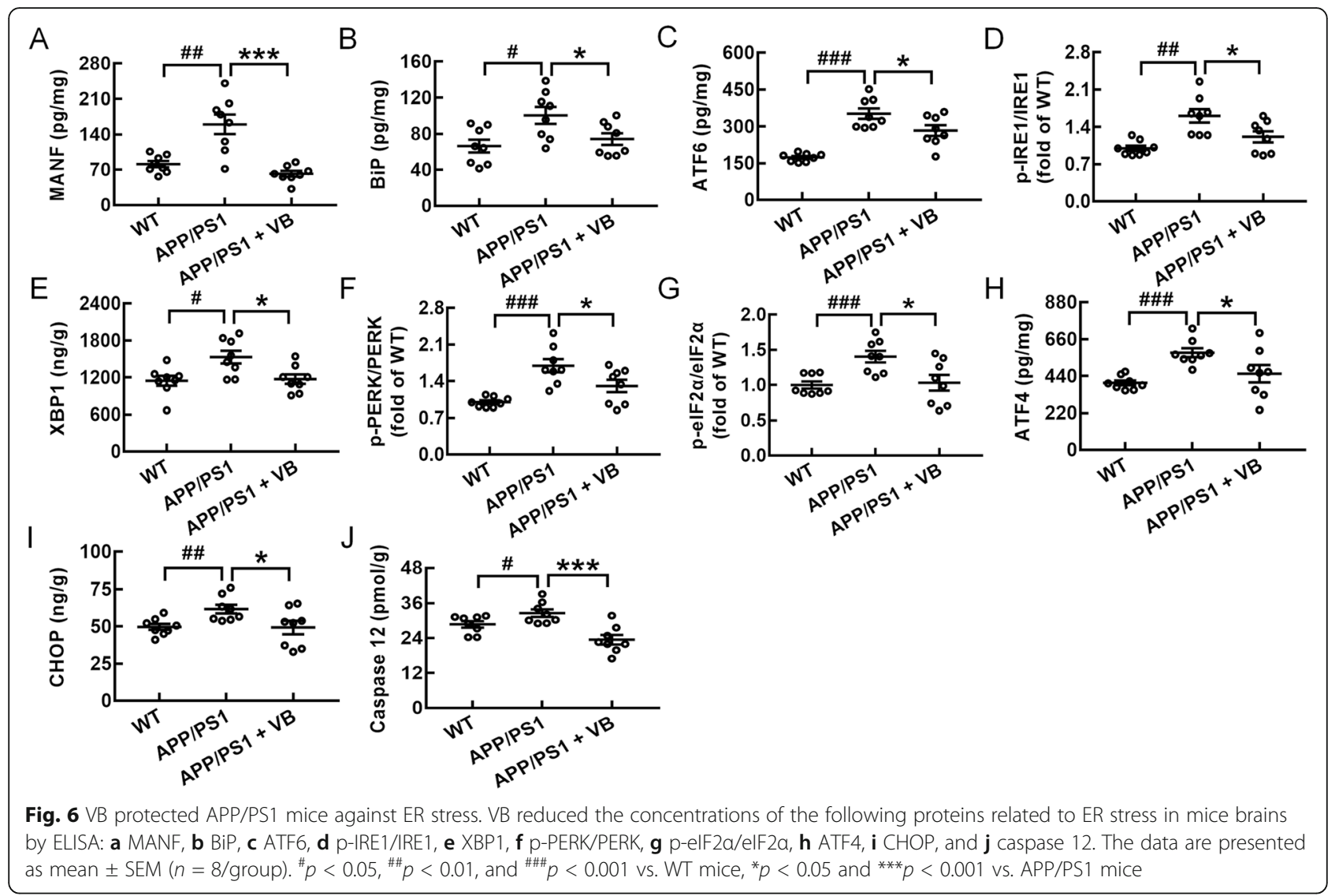

stress [5]. Subsequently, continuous ER stress induces hyperphosphorylation of tau, which initiates a vicious cycle and aggravates the AD process [26]. Furthermore, ER stress and over-accumulation of ROS in the brain promote lipid peroxidation, generating 4-HNE, which inhibits dephosphorylation of tau [60]. Hyperphosphorylated tau shows much greater deleterious effects (via the formation of NFTs) on cognitive function than does $A \beta$ deposition, and as reported, knock-out of tau can inhibit $A \beta$-induced memory and cognitive impairment $[61,62]$. In this study, VB helped to improve the memory and cognitive ability of APP/PS1 mice.

Label-free quantification proteomics analysis was performed to screen for significantly differentially expressed proteins, and their interactions. Consistent with our findings, among the 26 proteins significantly influenced by VB, we identified MANF, an ER stress response protein. As a member of the fourth family of neurotrophic factors, MANF has been proven to protect and repair dopaminergic neurons and maintain the homeostasis of ER proteins $[42,43]$. According to our STRING protein interaction mapping analysis, MANF is found to interact with ATF4, XBP1, and ATF6. Knockout of MANF upregulates the expression of ATF4, XBP1, and ATF6 in cells [43]. As a transcription factor, ATF4 is responsible for controlling protein homeostasis in the ER [5], XBP1 activates the UPR target [47], and ATF6 targets UPRrelated proteins after activation [23]. Under chronic or irreversible ER stress, UPR activation promotes the release of $\mathrm{Ca}^{2+}$ in the ER and activates the intrinsic and extrinsic apoptotic pathways by regulating the $\mathrm{B}$ cell lymphoma 2 (Bcl-2) and caspase protein families [63]. Based on the results of TEM of U251 cells and label-free quantification proteomics analysis, we speculate that VB improves the pathological condition of $\mathrm{AD}$ mice, possibly due to its regulation of ER stress.

Furthermore, ELISA and western blot analysis were performed to detect the concentrations of related proteins screened by label-free quantitative proteomics analysis in APP/PS1 mice brains and $A \beta_{1-42}$-exposed U251 cells. Surprisingly, these proteins belong to the three branches of UPR signaling: PERK/eIF2 $\alpha / A T F 4$, IRE1/XBP1, and ATF6. According to previous reports, ATF4 is a downstream target of PERK/eIF2 $\alpha$. Activated PERK promotes the phosphorylation of eIF2 $\alpha$, which further improves the efficiency of translation of ATF4. CHOP is activated by ATF4 and triggers cell death programs by regulating $\mathrm{Bcl}-2$, AKT, and JNK $[5,24]$. XBP1 is a downstream target of IRE1. IRE1 is auto-phosphorylated after dissociating from $\mathrm{BiP}$ and promotes the unconventional digestion of XBP1 mRNA into XBP1s [24], which mediates apoptosis by 


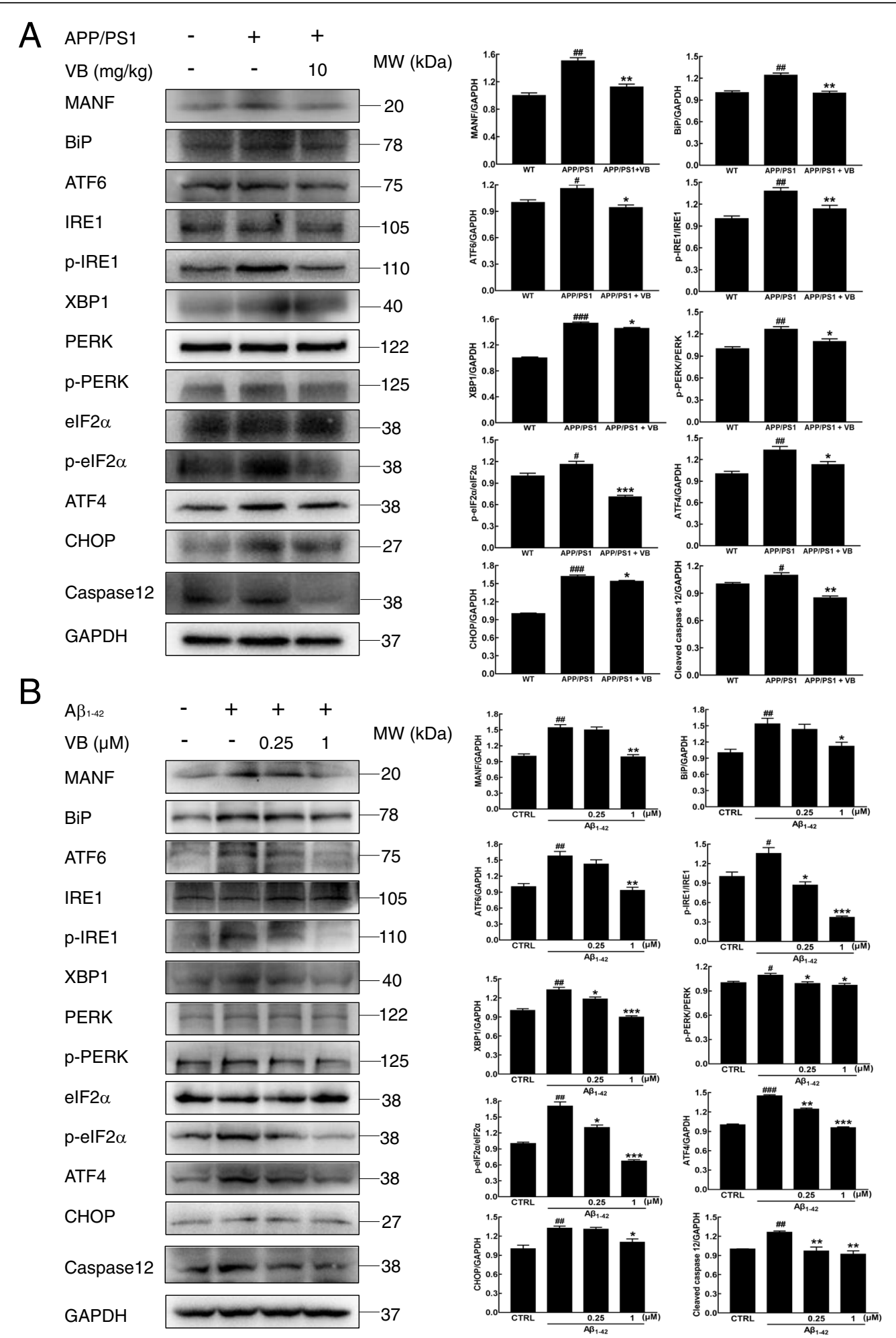

Fig. $7 \mathrm{VB}$ attenuated $E R$ stress in APP/PS1 mice and $A \beta_{1-42}$-exposed $U 251$ cells. VB reduced the expression levels of MANF, BiP, ATF6, XBP1s, ATF4, CHOP, and caspase 12 and the levels of phosphorylated IRE1, PERK, and elF2 $a$ in a the brain lysates of APP/PS1 mice and $\mathbf{b}$ A $\beta_{1-42}$-exposed U251 cells. GAPDH was used as a loading control and for band-density normalization. Phosphorylated proteins were normalized using the related total protein concentration. The data are presented as means \pm SEM $\left(n=4 /\right.$ group). ${ }^{\#} p<0.05,{ }^{\# \#} p<0.01$, and ${ }^{\# \# \# p} p<0.001$ vs. WT mice or non-treated

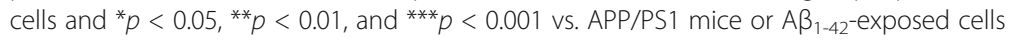


increasing the activation of caspases [64]. In the case of ER stress, ATF6 is separated from BiP and translocated to the Golgi apparatus, where it is lysed by the proteases SP1 and SP2 to generate ATF6f, which induces cell apoptosis [5, 43]. In this study, we found that VB inhibited all three of the branches of the UPR signal, thereby preventing ER stress and, in turn, delaying the progress of $\mathrm{AD}$. Our data suggest the important roles of VB-mediated protection during ER stress against $\mathrm{AD}$-like symptoms.

In summary, we found that VB relieved ER stress by inhibiting the UPR signal and enhancing mitochondrial and ER morphology in $A \beta_{1-42}$-exposed U251 cells. Simultaneously, VB relieved the pathological condition of APP/PS1 mice, thereby improving their memory and cognitive ability. However, the specific target and binding sites of VB are still unknown. Furthermore, how VB prevents apoptosis by improving ER stress should be verified in future research. Recently, it has been reported that ER stress can cause inflammation and that this leads to neuronal apoptosis and synaptic loss [65]. In future research, we will therefore explore the molecular mechanism of the neuroprotective effects of VB in greater depth. Finally, we did not measure how much VB passes through the blood brain barrier, so we do not know whether VB directly targets brain cells or reduces systemic ER stress and indirectly attenuate neuronal ER stress.

\section{Conclusions}

To the best of our knowledge, this is the first study to report that the neuroprotective effects of $\mathrm{VB}$ against $\mathrm{AD}$ in APP/PS1 mice and $A \beta_{1-42}$-exposed $U 251$ cells occurs via VB increasing resistance to ER stress. Our findings support the role of VB as a candidate agent for further research as an $\mathrm{AD}$ remedy, which also support the hypothesis that ER stress mediates the progression of $\mathrm{AD}$ [23]. Further mechanism study is needed to illustrate the molecular mechanism of $\mathrm{VB}$ and the contribution of ER stress in the progression of $\mathrm{AD}$.

\section{Supplementary information}

Supplementary information accompanies this paper at https://doi.org/10. 1186/s12974-020-01976-1.

Additional file 1: Figure S1. The structure of verbascoside (Cas.NO 61276-17-3). Figure S2 The changes on body weight of APP/PS1 mice during the six-week experimental period. $(n=12) . p>0.05$ vs. WT mice, and $p>0.05$ vs. APP/PS1 mice. Data are the mean \pm SEM. Figure S3 VB showed no significant pathologic alternations on (A) spleen, (B) liver and (C) kidneys of mice via $\mathrm{H}$ \& E staining (Magnification $\times 20$, Scale bar: 50 $\mu \mathrm{m})(n=3)$. Figure $\mathbf{S} 4 \mathrm{VB}$ reduced the levels of $(\mathbf{A})$ caspase $3,(\mathbf{B})$ caspase 8 and (C) ROS, and increased (D) IDE in brain of APP/PS1 mice analyzing via ELISA $(n=8)$. ${ }^{\#} p<0.05$ and ${ }^{\# \#} p<0.01$ vs. WT mice, and ${ }^{*} p<$ 0.05 and $^{* * *} p<0.001$ vs. APP/PS1 mice. Data are the mean \pm SEM.

\section{Abbreviations}

AD: Alzheimer's disease; ATF4: Activating transcription factor-4; ATF6: Activating transcription factor-6; APP/PS1: APPswe/PSEN1dE9 transgenic; ARRIVE: Animal Research: Reporting In Vivo Experiments; A $\beta$ : Amyloid $\beta ;$ BCl-2: B cell lymphoma 2; BiP: Immunoglobulin-binding protein; CHOP: C/EBP-homologous protein; elF2a: Eukaryotic initiation factor 2; ELISA: Enzyme-linked immunosorbent assay; ER: Endoplasmic reticulum; H\&E: Hematoxylin and eosin; IDE: Insulin-degrading enzyme; IRE1: Inositolrequiring protein 1; MANF: Mesencephalic astrocyte-derived neurotrophic factor; MWM: Morris water maze; NFTs: Neurofibrillary tangles; OFT: Openfield test; PERK: Pancreatic ER kinase; PMSF: Phenylmethanesulfonyl fluoride; RIPA: Radio-immunoprecipitation assay; ROS: Reactive oxygen species; SEM: Means \pm standard errors of the mean; TEM: Transmission electron microscopy; TUNEL: Terminal deoxynucleotidyl transferase-mediated deoxyuridine triphosphate nick end labeling; UPR: Unfolded protein response; U251: Human glioma; VB: Verbascoside; WT: Wild-type; XBP1: X-box binding protein 1; 4-HNE: 4-Hydroxynonenal

\section{Acknowledgments}

Not applicable.

\section{Authors' contributions}

Di Wang and Yizhi Zhang conceived and designed this experiment. Chunyue Wang, Xueying Cai, Ruochen Wang, Siyu Zhai, Yongfeng Zhang, and Wenji Hu peformed the experiment within Di Wang's instruction. Chunyue Wang and Xueying Cai analyzed the results and wrote the main manuscript. Di Wang and Yizhi Zhang revised the manuscript. The authors read and approved the final manuscript.

\section{Funding}

This work was supported by the National Key Research \& Development Program of China (Grant No. 2018YFE0107800); the "13 $3^{\text {th }}$ Five-year" Science and Technology Projects from Education Department in Jilin Province of P. R. China (Grant No. JJKH20190108KJ) and Industrial Technology Research and Development Projects from Development and Reform Commission of Jilin Province of P. R. China (Grant No. 2019C050-8).

\section{Availability of data and materials}

The datasets used and/or analyzed during the current study are available from the corresponding author on reasonable request.

\section{Ethics approval and consent to participate}

The experiments complied with the ARRIVE guidelines and were carried out in accordance with the National Institutes of Health Guide for the Care and Use of Laboratory Animals and obtained an ethical review form regarding animal welfare approved by the Experimental Animal Center of Jilin University (No. SY201905014).

Consent for publication Not applicable.

\section{Competing interests}

The authors declare that they have no competing interests.

Received: 6 September 2020 Accepted: 1 October 2020 Published online: 18 October 2020

\section{References}

1. Park JC, Han SH, Yi D, Byun MS, Lee JH, Jang $S$, et al. Plasma tau/amyloidbeta(1-42) ratio predicts brain tau deposition and neurodegeneration in Alzheimer's disease. Brain. 2019;142:771-86.

2. 2020 Alzheimer's disease facts and figures. Alzheimers Dement. 2020;16(3): 391-460.

3. Chen S, Chen ST, Sun Y, Xu Z, Wang Y, Yao SY, et al. Fibroblast growth factor 21 ameliorates neurodegeneration in rat and cellular models of Alzheimer's disease. Redox Biol. 2019;22:9.

4. Uddin MS, Kabir MT, Al Mamun A, Abdel-Daim MM, Barreto GE, Ashraf GM. APOE and Alzheimer's disease: evidence mounts that targeting APOE4 may combat Alzheimer's pathogenesis. Mol Neurobiol. 2019;56(4):2450-65.

5. Gerakis $Y$, Hetz C. Emerging roles of ER stress in the etiology and pathogenesis of Alzheimer's disease. FEBS J. 2018;285(6):995-1011. 
6. Mawuenyega KG, Sigurdson W, Ovod V, Munsell L, Kasten T, Morris JC, et al. Decreased clearance of CNS beta-amyloid in Alzheimer's disease. Science. 2010, 6012;330:1774.

7. Xu MJ, Yan TX, Fan KY, Wang MS, Qi Y, Xiao F, et al. Polysaccharide of Schisandra chinensis Fructus ameliorates cognitive decline in a mouse model of Alzheimer's disease. J Ethnopharmacol. 2019;237:354-65.

8. Wang J, Gu BJ, Masters CL, Wang YJ. A systemic view of Alzheimer disease-insights from amyloid-beta metabolism beyond the brain. Nat Rev Neurol. 2017;13(10):612-23.

9. Hort J, Valis M, Angelucci F. Administration of pre/probiotics with conventional drug treatment in Alzheimer's disease. Neural Regen Res. 2020;15(3):448-9.

10. Savelieff MG, Nam G, Kang J, Lee HJ, Lee M, Lim MH. Development of multifunctional molecules as potential therapeutic candidates for Alzheimer's disease, Parkinson's disease, and amyotrophic lateral sclerosis in the last decade. Chem Rev. 2019;119(2):1221-322.

11. Chalupova K, Korabecny J, Bartolini M, Monti B, Lamba D, Caliandro R, et al. Novel tacrine-tryptophan hybrids: multi-target directed ligands as potential treatment for Alzheimer's disease. Eur J Med Chem. 2019;168: 491-514.

12. Burns A, Rossor M, Hecker J, Gauthier S, Petit H, Moller HJ, et al. The effects of donepezil in Alzheimer's disease-results from a multinational trial. Dement Geriatr Cogn Disord. 1999;10(3):237-44.

13. Grossberg G, Meng XY, Olin JT. Impact of rivastigmine patch and capsules on activities of daily living in Alzheimer's disease. Am J Alzheimers Dis Other Dement. 2011;26(1):65-71.

14. Kitagawa N, Sakurai M. Memantine-induced sustained unconsciousness. Neurol Clin Neurosci. 2016;4(6):236-8

15. Wang $X Y$, Sun GQ, Feng $T$, Zhang J, Huang $X$, Wang $T$, et al. Sodium oligomannate therapeutically remodels gut microbiota and suppresses gut bacterial amino acids-shaped neuroinflammation to inhibit Alzheimer's disease progression. Cell Res. 2019:29(10):787-803.

16. Wang $H Q$, Xu YX, Yan J, Zhao XY, Sun XB, Zhang YP, et al. Acteoside protects human neuroblastoma SH-SY5Y cells against beta-amyloid-induced cell injury. Brain Res. 2009;1283:139-47.

17. Wang J, Ma CH, Wang SM. Effects of acteoside on lipopolysaccharideinduced inflammation in acute lung injury via regulation of NF-kappa B pathway in vivo and in vitro. Toxicol Appl Pharmacol. 2015;285(2): $128-35$.

18. Li MQ, Zhou F, Xu T, Song HX, Lu BY. Acteoside protects against 6-OHDAinduced dopaminergic neuron damage via Nrf2-ARE signaling pathway. Food Chem Toxicol. 2018;119:6-13.

19. Campo G, Pavasini R, Biscaglia S, Ferri A, Andrenacci E, Tebaldi M, et al. Platelet aggregation values in patients with cardiovascular risk factors are reduced by verbascoside treatment. A randomized study. Pharmacol Res. 2015;97:1-6

20. Peng XM, Gao L, Huo SX, Liu XM, Yan M. The mechanism of memory enhancement of acteoside (Verbascoside) in the senescent mouse model induced by a combination of d-gal and AICl3. Phytother Res. 2015;29(8): 1137-44.

21. Lee KY, Jeong EJ, Lee HS, Kim YC. Acteoside of Callicarpa dichotoma attenuates scopolamine-induced memory impairments. Biol Pharm Bull. 2006;29(1):71-4.

22. Kurisu M, Miyamae Y, Murakami K, Han J, Isoda H, Irie K, et al. Inhibition of amyloid beta aggregation by acteoside, a phenylethanoid glycoside. Biosci Biotechnol Biochem. 2013;77(6):1329-32.

23. Hosoi T, Nomura J, Ozawa K, Nishi A, Nomura Y. Possible involvement of endoplasmic reticulum stress in the pathogenesis of Alzheimer's disease. Endoplasmic Reticulum Stress Dis. 2015;2(1):107-18.

24. Li YR, Jiang WY, Niu QN, Sun YJ, Meng CC, Tan L, et al. elF2 alpha-CHOP$\mathrm{BCl}-2 / \mathrm{JNK}$ and IRE1 alpha-XBP1/JNK signaling promote apoptosis and inflammation and support the proliferation of Newcastle disease virus. Cell Death Dis. 2019;10:15.

25. Kudo T, Okumura M, Imaizumi K, Araki W, Morlhara T, Tanimukal H, et al. Altered localization of amyloid precursor protein under endoplasmic reticulum stress. Biochem Biophys Res Commun. 2006; 344(2):525-30

26. Ho YS, Yang XF, Lau JCF, Hung CHL, Wuwongse S, Zhang QS, et al. Endoplasmic reticulum stress induces tau pathology and forms a vicious cycle: implication in Alzheimer's disease pathogenesis. J Alzheimers Dis. 2012;28(4):839-54
27. Hong Y, Wang XM, Sun S, Xue G, Li JL, Hou YN. Progesterone exerts neuroprotective effects against a beta-induced neuroinflammation by attenuating ER stress in astrocytes. Int Immunopharmacol. 2016;33:83-9.

28. Alberdi E, Wyssenbach A, Alberdi M, Sanchez-Gomez MV, Cavaliere F, Rodriguez JJ, et al. Ca2+-dependent endoplasmic reticulum stress correlates with astrogliosis in oligomeric amyloid-treated astrocytes and in a model of Alzheimer's disease. Aging Cell. 2013;12(2):292-302.

29. Holden LJ, Coleman MD. Assessment of the astrogliotic responses of three human astrocytoma cell, lines to ethanol, trimethyltin chloride and acrylamide. Toxicology. 2007;241(1-2):75-83.

30. Zeuner MT, Vallance T, Vaiyapuri S, Cottrell GS, Widera D. Development and characterisation of a novel NF-kappa B reporter cell line for investigation of neuroinflammation. Mediat Inflamm. 2017;2017:10.

31. Handattu SP, Monroe CE, Nayyar G, Palgunachari MN, Kadish I, van Groen T, et al. In vivo and in vitro effects of an apolipoprotein $E$ mimetic peptide on amyloid-beta pathology. J Alzheimers Dis. 2013;36(2):335-47.

32. Zhang DF, Li J, Wu H, Cui Y, Bi R, Zhou HJ, et al. CFH variants affect structural and functional brain changes and genetic risk of Alzheimer's disease. Neuropsychopharmacology. 2016;41(4):1034-45.

33. Li ZP, Chen X, Zhang YF, Liu X, Wang CY, Teng LS, et al. Protective roles of amanita caesarea polysaccharides against Alzheimer's disease via Nrf2 pathway. Int J Biol Macromol. 2019;121:29-37.

34. Yang YJ, He ZT, Xing ZW, Zuo ZJ, Yuan LF, Wu YY, et al. Influenza vaccination in early Alzheimer's disease rescues amyloidosis and ameliorates cognitive deficits in APP/PS1 mice by inhibiting regulatory T cells. J Neuroinflamm. 2020;17(1):17.

35. Wang DM, Li SQ, Chen J, Liu L, Zhu XY. The effects of astilbin on cognitive impairments in a transgenic mouse model of Alzheimer's disease. Cell Mol Neurobiol. 2017;37(4):695-706.

36. Zhang XR, Chen YL, Cai GS, Li X, Wang D. Carnosic acid induces apoptosis of hepatocellular carcinoma cells via ROS-mediated mitochondrial pathway. Chem Biol Interact. 2017:277:91-100.

37. An SS, Lu WQ, Zhang YF, Yuan QX, Wang D. Pharmacological basis for use of Armillaria mellea polysaccharides in Alzheimer's disease: antiapoptosis and antioxidation. Oxidative Med Cell Longev. 2017;2017:11.

38. Lin WZ, Xu YY, Chen XC, Liu J, Weng YL, Zhuang QY, et al. Radiationinduced small extracellular vesicles as "carriages" promote tumor antigen release and trigger antitumor immunity. Theranostics. 2020; 10(11):4871-84.

39. Hu WJ, Wang J, Guo WY, Liu YG, Guo Z, Miao YG, et al. Studies on characteristics and anti-diabetic and -nephritic effects of polysaccharides isolated from Paecilomyces hepiali fermentation mycelium in $\mathrm{db} / \mathrm{db}$ mice. Carbohydr Polym. 2020;232:11.

40. Li T, Jiao JJ, Holscher C, Wu MN, Zhang J, Tong JQ, et al. A novel GLP-1/GIP/ Gcg triagonist reduces cognitive deficits and pathology in the $3 \times \mathrm{Tg}$ mouse model of Alzheimer's disease. Hippocampus. 2018;28(5):358-72.

41. Tsirulnikov K, Abuladze N, Bragin A, Faull K, Cascio D, Damoiseaux R, et al. Inhibition of aminoacylase 3 protects rat brain cortex neuronal cells from the toxicity of 4-hydroxy-2-nonenal mercapturate and 4-hydroxy-2-nonenal. Toxicol Appl Pharmacol. 2012;263(3):303-14.

42. Renko JM, Back S, Voutilainen MH, Piepponen TP, Reenila I, Saarma M, et al. Mesencephalic astrocyte-derived neurotrophic factor (MANF) elevates stimulus-evoked release of dopamine in freely-moving rats. Mol Neurobiol. 2018;55(8):6755-68.

43. Xu SC, Di ZM, He YF, Wang RJ, Ma YY, Sun R, et al. Mesencephalic astrocytederived neurotrophic factor (MANF) protects against a beta toxicity via attenuating a beta-induced endoplasmic reticulum stress. J Neuroinflamm. 2019;16:14.

44. Tseng KY, Danilova T, Domanskyi A, Saarma M, Lindahl M, Airavaara M. MANF is essential for Neurite extension and neuronal migration in the developing cortex. eNeuro. 2017;4(5):21.

45. Yan YH, Rato C, Rohland L, Preissler S, Ron D. MANF antagonizes nucleotide exchange by the endoplasmic reticulum chaperone BiP. Nat Commun. 2019;10:15.

46. Guo Q, Hu HL, Liu XH, Yang DQ, Yin Y, Zhang BY, et al. C/EBP beta mediates palmitate-induced musclin expression via the regulation of PERKJATF4 pathways in myotubes. Am J Physiol-Endocrinol Metab. 2019;316(6):E1081-E92.

47. Duran-Aniotz C, Cornejo VH, Espinoza S, Ardiles AO, Medinas DB, Salazar C, et al. IRE1 signaling exacerbates Alzheimer's disease pathogenesis. Acta Neuropathol. 2017;134(3):489-506. 
48. Ohno M. Roles of elF2 alpha kinases in the pathogenesis of Alzheimer's disease. Front Molec Neurosci. 2014;7:8.

49. Huang RR, Hu W, Yin YY, Wang YC, Li WP, Li WZ. Chronic restraint stress promotes learning and memory impairment due to enhanced neuronal endoplasmic reticulum stress in the frontal cortex and hippocampus in male mice. Int J Mol Med. 2015;35(2):553-9.

50. Wang $\mathrm{H}$, Dong $\mathrm{Y}$, Zhang J, Xu Z, Wang G, Swain CA, et al. Isoflurane induces endoplasmic reticulum stress and caspase activation through ryanodine receptors. Br J Anaesth. 2014;113(4):695-707.

51. Xu HX, Yan Y, Li L, Peng SG, Qu T, Wang BX. Ultraviolet B-induced apoptosis of human skin fibroblasts involves activation of caspase- 8 and-3 with increased expression of vimentin. Photodermatol Photoimmunol Photomed. 2010;26(4):198-204.

52. Kim BM, Chung HW. Hypoxia/reoxygenation induces apoptosis through a ROS-mediated caspase-8/bid/Bax pathway in human lymphocytes. Biochem Biophys Res Commun. 2007;363(3):745-50.

53. Tonnies E, Trushina E. Oxidative stress, synaptic dysfunction, and Alzheimer's disease. J Alzheimers Dis. 2017;57(4):1105-21.

54. Vepsalainen S, Hiltunen M, Helisalmi S, Wang J, van Groen T, Tanila H, et al. Increased expression of a beta degrading enzyme IDE in the cortex of transgenic mice with Alzheimer's disease-like neuropathology. Neurosci Lett. 2008;438(2):216-20.

55. Sun KH, de Pablo Y, Vincent F, Shah K. Deregulated Cdk5 promotes oxidative stress and mitochondrial dysfunction. J Neurochem. 2008;107(1): $265-78$.

56. Di Meo S, Reed TT, Venditti P, Victor VM. Role of ROS and RNS sources in physiological and pathological conditions. Oxidative Med Cell Longev. 2016;44.

57. Swerdlow RH, Burns JM, Khan SM. The Alzheimer's disease mitochondrial cascade hypothesis: progress and perspectives. Biochim Biophys Acta-Mol Basis Dis. 2014;1842(8):1219-31.

58. Omar SH, Kerr PG, Scott CJ, Hamlin AS, Obied HK. Olive (Olea europaea L.) biophenols: a nutriceutical against oxidative stress in SH-SY5Y cells. Molecules. 2017;22(11):20.

59. Nagakura A, Shitaka Y, Yarimizu J, Matsuoka N. Characterization of cognitive deficits in a transgenic mouse model of Alzheimer's disease and effects of donepezil and memantine. Eur J Pharmacol. 2013;703(1-3):53-61.

60. Zhou SS, Yu GC, Chi LJ, Zhu JW, Zhang W, Zhang Y, et al. Neuroprotective effects of edaravone on cognitive deficit, oxidative stress and tau hyperphosphorylation induced by intracerebroventricular streptozotocin in rats. Neurotoxicology. 2013;38:136-45.

61. Andrews-Zwilling Y, Bien-Ly N, Xu Q, Li G, Bernardo A, Yoon SY, et al. Apolipoprotein E4 causes age- and tau-dependent impairment of GABAergic interneurons, leading to learning and memory deficits in mice. J Neurosci. 2010;30(41):13707-17.

62. Selkoe DJ, Hardy J. The amyloid hypothesis of Alzheimer's disease at 25 years. EMBO Mol Med. 2016;8(6):595-608.

63. Naidoo N. ER and aging - protein folding and the ER stress response. Ageing Res Rev. 2009;8(3):150-9.

64. Valentine CD, Anderson MO, Papa FR, Haggie PM. X-box binding protein 1 (XBP1s) is a critical determinant of Pseudomonas aeruginosa homoserine lactone-mediated apoptosis. PLoS Pathog. 2013;9(8):13.

65. Liu YA, Gong YC, Xie WJ, Huang AL, Yuan XY, Zhou H, et al. Microbubbles in combination with focused ultrasound for the delivery of quercetin-modified sulfur nanoparticles through the blood brain barrier into the brain parenchyma and relief of endoplasmic reticulum stress to treat Alzheimer's disease. Nanoscale. 2020;12(11):6498-511.

\section{Publisher's Note}

Springer Nature remains neutral with regard to jurisdictional claims in published maps and institutional affiliations.

Ready to submit your research? Choose BMC and benefit from:

- fast, convenient online submission

- thorough peer review by experienced researchers in your field

- rapid publication on acceptance

- support for research data, including large and complex data types

- gold Open Access which fosters wider collaboration and increased citations

- maximum visibility for your research: over $100 \mathrm{M}$ website views per year

At BMC, research is always in progress.

Learn more biomedcentral.com/submissions 